\title{
HUMAN BIOCHEMICAL GENETICS
}

\begin{abstract}
$\triangle$ JOINT SESSION arranged by Sections $D$ (Zoology), I (Physiology), J (Psychology) and $\mathrm{K}$ (Botany) of the British Association was held during the recent Belfast meeting to discuss "Human Biochemical Genetics".

In his introductory remarks, Prof. L. S. Penrose (Galton Laboratory, University College, London) pointed out that the foundations of the exact study of human genetics were laid down almost simultaneously by Landsteiner in his work on the $A B O$ blood groups and by Garrod in his work on alkaptonuria. These investigations, carried out between 1900 and 1902, described human characters which were found to follow simple rules of inheritance, and the tests for their presence or absence were precise. The branch of the subject initiated by Landsteiner utilized serological techniques depending ultimately, but not yet demonstrably, upon inborn biochemical peculiarities. The other branch of biochemical studies in human genetics is derived from Garrod's work, and it deals with characters identified by ordinary chemical tests or their equivalents, like colour reactions.

It is convenient to classify the known types of inborn biochemical specifications by the substances involved in the test reactions. Anomalies of protein metabolism include alkaptonuria, the amino-acidurias, such as phenylketonuria, tyrosinosis, cystinuria and beta-aminoisobutyricaciduria (the 'T-pattern' described by Crumpler, Dent, Harris and Westall), the melanin peculiarities exemplified by albinism and the globulin specificities found in the blood in sickle-cell trait and thalassæmia. Abnormal lipoid metabolism is represented by such diseases as xanthomatosis and cerebromacular degeneration; at present this group has proved intractable for experimental investigation. Anomalies associated with carbohydrate metabolism include pentosuria, fructosuria and renal glycosuria; diabetes mellitus is only included in a very indirect manner. There is also a large miscellaneous group of conditions, not easy to classify, some associated with disease and others quite harmless ; for example, gout, porphyria, congenital methæmoglobinæmia, red hair and taste deficiency.
\end{abstract}

A primary aim in human genetics is to reduce all characters so far as possible to chemical differences. In this way, the study of human constitution will gradually become an exact science freed from ambiguities and superstitions which surround the cult of physical types. Moreover, with harmful traits, knowledge of the causal mechanisms can help in planning their alleviation or cure.

Three aspects of the subject were emphasized by Dr. H. Harris (University College, London): the precise characterization of human variations in biochemical terms, the genetical analysis of traits so defined, and the study of the processes by which individual genes produce their particular effects. 'These points were illustrated by reference to aminoacidurias in general and especially to cystinuria, a condition first recognized by Wollaston in 1810 on the discovery of a renal stone of unusual composition. Since the introduction of paper chromatography, it has been possible to separate a classical typo of cystinuria, in which cystine exeretion is accompanied by excessive excretion of lysine and arginine, from other types, in which it occurs as part of a generalized amino-aciduria (for example, Fanconi syndrome,
Wilson's disease). Quantitative studies using the technique of polarography were carried out in families containing cases of classical cystinuria. Those with stone formation were found to excrete on the average about $750 \mathrm{mgm}$. of cystine daily, whereas normal people averaged about $60 \mathrm{mgm}$. In one group of families studied, cystinuria segregates sharply and behaves as a single. Mendelian recessive trait. In the remainder of families, three distinct types of individuals were found: the data here were consistent with the hypothesis that heterozygotes (carriers of the gene causing cystinuria in homozygotes) excreted about $150 \mathrm{mgm}$. daily and were thus distinguishable from normal homozygotes. 'The frequency of carriers of this incompletely recessive gene is about 3 per 1,000 in the general population.

Garrod's view on the causation of biochemical anomalies was that there was congenital absence of an enzyme concermed in performing a particular step in metabolism. This theory is easy to apply to alkaptonuria and phenylketonuria; but in renal glycosuria or cystinuria the process is not so clearly demonstrable. A block in intermediate metabolism would tend (as it does in phenylketonuria) to cause an increase of unusable metabolites in the bloodstream or tissue-fluids. This does not occur in classical cystinuria, and it is thought that there is failure of reabsorption in the kidney tubules due to a defect in one of the chemical reactions concerned in this complex process.

A detailed account of the effects of the recessive gene for phenylketonuria in its homozygous form was given by Dr. V. Cowie (Maudsley Hospital, London). In this disease, first described by Fölling in 1934, about $1 \mathrm{gm}$. of phenylpyruvic acid is excreted daily in the urine. Dr. Cowie pointed out that mental impairment, usually of a severe degree, is always present, and there are many associated physical features including dilution of hair colour and postural peculiarities. The fundamental defect is a reduced capacity to metabolize phenylalanine through the normal channel by way of tyrosine. Experiments have shown that although this pathway is not completely blocked, phenylalanine accumulates in the blood and cerebrospinal fluid and is eventually excreted after deaminization as phenylpyruvic acid. The way in which the mental and physical abnormalities are produced by the biochemical defect, she said, is not yet clear. However, the condition is present at birth, and attempts at alleviation by dietetic methods have so far been unsuccessful, though the possibilities of very early treatment have not been fully explored.

Besides demonstrating hereditary biochemical specificities within the human species, Garrod directed attention to the biochemical differences between species. An account of a comparative survey of urinary amino-acid patterns in a number of different animal species was given by Dr. S. P. Datta (University College, London). Most of the animals tested were in the London Zoo. Sufficient urine was placed on two-dimensional chromatograms to give up to six main spots. Glycine was almost always present, and alanine and glutamine or glutamic acid occurred very frequently. In the mouse and the binturong, however, only taurine was found. One substance of special interest, a sulphur-containing amino-acid, 
purified from cats' urine by Westall, was named 'cat-spot'. In most of the Felidæ it appears to be an alternative to taurine for the excretion of organic sulphur. The Kenya blotched genet has a peculiarity unique among the animals studied in that it excretes very large quantities of cystine. The question as to how so much cystine can be kept in solution in these urines might have some relevance to the study of the prevention of cystine-stone formation in man.

Dr. Datta showed that methyl histidine, which occurs variably in human urine, is always present in laboratory cats which are fed mainly on meat. It is not excreted by animals such as rats, mice, rabbits and guinea pigs, the diets of which are mostly of vegetable origin. By experiments on man, it has been possible to demonstrate that methyl histidine in the urine is probably derived from ingested anserine, a known constituent of muscle. Anserine is hydrolysed in the body to produce beta-alanine, which is further metabolized, and methyl histidine, which is excreted. Thus a peculiarity which superficially resembles an inborn trait turns out on chemical analysis to be mainly a question of diet.

Prof. D. C. Harrison (Queen's University, Belfast) dealt with the rare hereditary disease familial methæmoglobinæmia. He reviewed work done in collaboration with Prof. H. Barcroft, Dr. Q. H. Gibson and others. In methæmoglobinæmia, an abnormally large proportion of the blood pigment hæmoglobin $(\mathrm{Hb})$ is changed to the corresponding ferric compound methæmoglobin $(M e t-H b)$, which is useless for oxygen transport. In normal blood, the equilibrium $H b \stackrel{\longmapsto}{\rightleftharpoons}$ Met-Hb lies far to the left owing to the action of enzyme oxidation-reduction systems in the red blood corpuscles. These systems reduce the methæmoglobin which is constantly being formed from hæmoglobin and prevent the methæmoglobin from accumulating in more than traces. In the type of methæmoglobinæmia caused by certain drugs or (in infants) by nitrates in drinking water, the oxidation of hæmoglobin to methæmoglobin becomes so fast that the restoring enzyme systems are temporarily unable to maintain the normal level of hæmoglobin; but conditions return to normal when the offending agent is removed. In familial methæmoglobinæmia, on the other hand, the rate of production of methæmoglobin is normal but its rate of reduction is abnormally slow, so that it may accumulate to form as much as 40 per cent or more of the total blood pigment. Denny observed that large doses of ascorbic acid (acting as a reducing agent) shift the equilibrium back towards normal.

The work of Gibson has shown that the disease is due to an enzyme defect in the red blood cells; there is a shortage of diaphorase I (a flavoprotein enzyme). This shortage was demonstrated by direct assay in the blood of all seven patients who were tested. The values were in every case lower than those of any of the sixteen normal bloods used for comparison. Addition of excess diaphorase I restored full activity. The oxygen dissociation curve of the blood of the patients was found to be shifted to the left, that is, the blood parted with its oxygen less readily than normal. This, coupled with the large amount of pigment present in the abnormal, non-functional state, mrkes it surprising that the patients as a whole were able to lead active, energetic lives. The compensating polycythæmia which was present in the more severe cases may help to explain this.

The disease is apparently due to a mutation of the gene responsible for synthesis of the flavoprotein diaphorase I. In all three families studied, the disease appeared to $b^{6} \theta$ inherited as a recessive Mendelian trait. Prof. Harrison stated that quantitative studies on the blood of relatives of the patients had given no evidence for the presence of detectable genetic carriers. 'I'reatment of the patients (which was successful in all cases) consisted of large daily doses of ascorbic acid continued indefinitely, preferably supplemented by a single dose of methylene blue after the first fow days.

\section{GROWING-POINTS IN CYTOLOGY}

$\mathrm{O}^{\mathrm{N}}$ the opening day of the recent British Association meeting in Belfast, a session was devoted by Section D (Zoology) to the discussion of some recent advances in cytology. The first paper, by $\mathrm{Mr}$. I. C. Smith (Dundee), on the curious cytology of Pharaoh's ant, Monomorium pharaonis L., followed naturally on Prof. Peacock's presidential address (see Nature, September 6, p. 395), which earlier in the day had been concerned with some aspects of hymenopteran reproduction. Pharaoh's ant shares with many other hymenopterans the peculiarity that the males arise from unfertilized eggs by haploid parthenogenesis, or arrhenotoky, with the result that the male germ cells and much of the soma remain haploid. The females, on the other hand, develop from fertilized eggs, so that the female germ cells and much of the soma are diploid. Clearly, the eggs of virgin females can develop only into males,

Since the male germ-line is already haploid, it is obvious that no further reduction can take place in the chromosome number during the maturation of spermatozoa. In the hornet, Meves showed as early as 1904 that, during spermatogenesis, the first meiotic division, which is normally a reduction division, is abortive, while oogenesis is normal. Considerable. attention has therefore been paid to the details of the first meiotic division in the spermatogenesis of Pharaoh's ant. Mr. Smith described the untidy nature of this division and the curious fact that about this time a small fragment of eytoplasm separates as a bud. Some have considered this bud to represent a vestigial cell, the remnant of a typical meiotic division; but there are now good reasons for abandoning this view. The division is, in fact, a normal mitosis, and the two daughter cells develop without any further division into spermatids and spermatozoa, which are, of course, haploid. There is therefore no stage in spermatogenesis which corresponds to a normal first meiotic division.

The meeting then passed on to consider an inter. esting paper by Dr. R. J. Goldacre (Chester Beatty Institute, London) on the tail region of Amoeba. Dr. Goldacre began by tilting at the insistence of so many zoologists that the Amoba is an animal without form, a point of view that is perpetuated by such names as Amoeba chaos and Chaos chaos. A text-book Amceba is said to throw out pseudopodia at random from any part of its surface, whereas the real $A$ moeba has an obvious antero-posterior polarity with a wellmarked permanent tail, or rear contracting end. This rear end can easily be distinguished as a group of wrinkles caused by a contraction of the cortical gel, which in the tail is liquefying to be squeezed forward up the central channel of the Amceba.

That the tail region of an $A m o b a$ is relatively permanent is shown by the fact that the animal has 